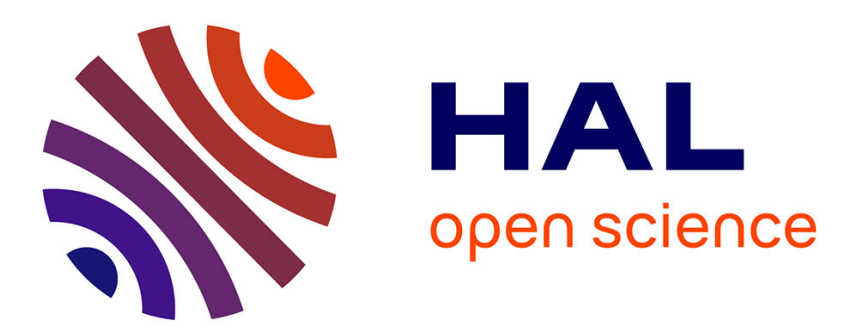

\title{
Infinity of God and Space of Men in Painting, Conditions of Possibility for the Scientific Revolution \\ Giuseppe Longo, Sara Longo
}

\section{To cite this version:}

Giuseppe Longo, Sara Longo. Infinity of God and Space of Men in Painting, Conditions of Possibility for the Scientific Revolution. Mathematics in the Visual Arts, 2020. hal-02904061

\section{HAL Id: hal-02904061 \\ https://hal.science/hal-02904061}

Submitted on 21 Jul 2020

HAL is a multi-disciplinary open access archive for the deposit and dissemination of scientific research documents, whether they are published or not. The documents may come from teaching and research institutions in France or abroad, or from public or private research centers.
L'archive ouverte pluridisciplinaire HAL, est destinée au dépôt et à la diffusion de documents scientifiques de niveau recherche, publiés ou non, émanant des établissements d'enseignement et de recherche français ou étrangers, des laboratoires publics ou privés. 


\section{Infinity of God and Space of Men in Painting, Conditions of Possibility for the Scientific Revolution ${ }^{1}$}

Giuseppe Longo

CNRS, École Normale Sup, Paris

https://www.di.ens.fr/users/longo/

\author{
Sara Longo \\ Ph.D., History of Art, Paris 1, Panthéon-Sorbonne \\ https://char.hypotheses.org/membres/sara-longo
}

\section{1 - A Brief Introduction to Infinity}

There is no space in Greek geometry. By drawing lines, using a ruler and a compass as we would say today, measurements are made and figures are constructed, with no mathematical "infinite container" - a plane or a space - "behind" them. Symmetries rotations and translations - provide proof in the finite. And potential infinity (apeiron, without limit, without bounds) is constructed by using extensions and iterations: a segment can be extended with no finite limit in a straight line (the second axiom), eis apeiron. If we take a set of prime numbers, we can construct a new prime which is greater than each of the elements in that set (Euclid's theorem on the infinitude of primes). An extension and an endless iteration of the finite, from the act of drawing a line to the construction of integers. Time is infinite in this sense, never present in its entirety in our mind. Infinity is not that beyond which there is nothing, Aristotle tells us in his Physics, but that beyond which there is always something. It is a becoming, a potentiality.

Paolo Zellini ${ }^{2}$ explains that the Aristotelian distinction between this mathematical infinity which must be constructed step by step, potential, and the infinity which is "already" there, in actuality, and is all-encompassing, was to resurface in medieval metaphysical debate. God is an all-enveloping, all-inclusive infinity, beyond which nothing is a given. But this concept of actual infinity is not an easy matter. For Aristotelians it was embodied in negation, as in Aristotle; and God cannot have a negative attribute. However, St. Thomas convinced people by excluding the existence of this kind of infinity in actuality, except as an attribute of God and God alone. And this concept of actual infinity was to grow in strength and acquire a positive identity in people's minds. This reached the point where, in 1277, the Bishop of Paris, Etienne Templier, was to decree actual infinity to be a positive attribute of God and His Creation. God, when He so wishes, introduces actual infinity also into the world; for example, by bestowing Full and Infinite Grace upon a finite being, a woman, Mary - and for those who disagreed, burning at stake awaited. There is no doubt that this uncompromising "axiomatic posture" helped stabilize the concept of actual infinity.

1 In Mathematics in the Visual Arts (R. Scheps and M.-C. Maurel ed.), ISTE-Wiley, 2020.

A significantly expanded and revised version of an article published in ISTE OpenScience - Published by ISTE Ltd, London, UK, 2019, and, in a very early form, in French in Le formalisme en action : aspects mathématiques et philosophiques, (J. Benoist and T. Paul eds), Hermann, 2013.

2 Zellini P., A Brief History of Infinity, Penguin, New York, 2005 (in Italian: Adelphi, Roma, 1980). 
Zellini quite rightly stressed the significance of this debate for the birth of a cosmology of infinity that was to find fulfilment, first mystical and then scientific, in the infinite Universe and "gli infiniti mondi" of Nicolas of Cusa (1401 - 1464) and Giordano Bruno (1548 - 1600).

\section{2 - Infinity in Painting and the Invention of Mathematical Space}

The concept of actual infinity was thus clarified in a metaphysical debate, circumscribing infinity as a single "entity" and forcing the mind to envisage it in its totality. How would it pass into mathematics, where it was to be turned into a specific object of discourse, and indeed an element of proof?

The transition came about through the invention of perspective (prospettiva) in Italian Renaissance painting ${ }^{3}$.

The problem of depicting the scenes where the narrative figures were to be placed became a central issue for painters from the late $13^{\text {th }}$ century onwards. Giottesque "boxes" (dolls' houses with one wall missing, exposed to the viewer) are scenes whose purpose is to contain the historia and to render intelligible its theological teachings. In a contiguous arrangement, the spatial scenes (boxes, landscape, hills) punctuate the narrative - we will come back to this later.

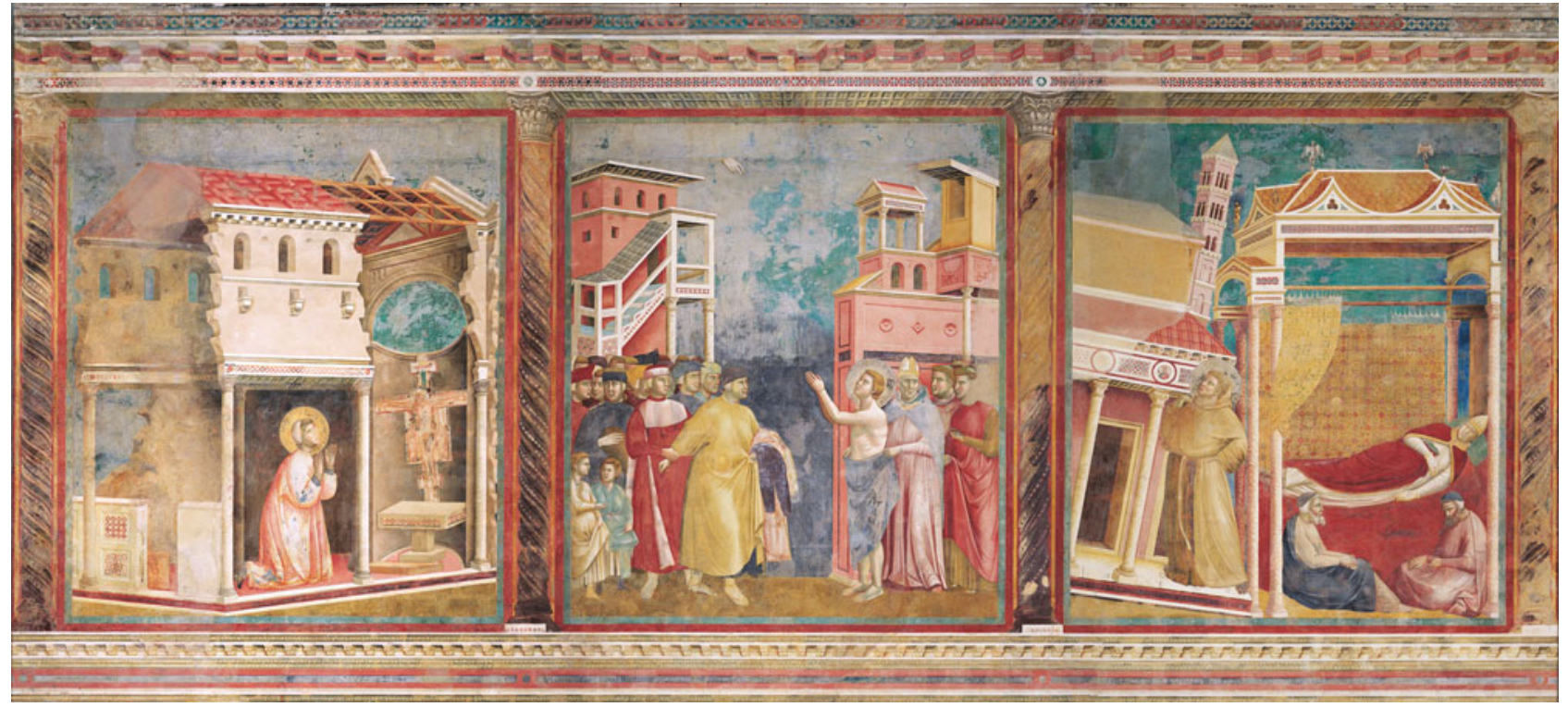

Giotto di Bondone, Life of St. Francis, fresco, around 1290. Assisi, Basilica of St. Francis

The geometrical perspective with which Filippo Brunelleschi experimented in 1417, and which was defined in 1435 by Leon Battista Alberti, is a revolution: not only does it construct a single compositional space (and thus, with a few rare exceptions, a unified narrative) but above all it is the result of a construction where man is the source of every

\footnotetext{
3 At the time there was intense debate in Italy over what name should be given to this new technique: perspettiva, "seeing through", which was to pass into other languages, or, more accurately, the choice of a viewpoint, a prospettiva, as we shall see.
} 
measurement (see Alberti, De Pictura, I, 19) and where actual infinity, the point of convergence of the orthogonal lines at the bottom of the painting, is contained, enclosed within the representational framework. Since the second half of the last century, in response to Erwin Panofsky's inaugural article (Perspective as Symbolic Form, 1925), art historians including Pierre Francastel, Hubert Damisch and Louis Marin from the École des Hautes Etudes en Sciences Sociales, in Paris, have highlighted the importance of this pictorial revolution.

According to Erwin Panofsky's foundational essay, published in Germany in 1927 but translated into English only in 1991, the representation of a space by the geometry of orthogonal lines led to the development of "the concept of an infinity, an infinity not only prefigured in God, but indeed actually embodied in empirical reality"4. Erwin Panofsky noted that Ambrogio Lorenzetti's Annunciation (below), painted a century before Alberti formulated his theory, is the first geometrical construction where the receding lines converge not towards a single point, but towards a single vertical axis (in the picture plane, the column separating Gabriel from Mary). Daniel Arasse went further, extending this insight to the quite remarkable upsurge in complex geometric constructions in scenes of the Annunciation to Mary.

His argument is very relevant to our discussion topic: the special affinity that existed in the $15^{\text {th }}$ century between Annunciation and perspective, is due to the fact that in Christian history, the moment at which the infinite enters into the finite is the moment when the son of God miraculously appears in human flesh, through the meeting of God and the Madonna, full of Grace. Daniel Arasse discusses this idea by highlighting what he calls a "theological-pictorial" problem that toys with the effects and the effectiveness of images: by a back and forth between depth and surface, the paradoxes internal to the spatial structures of certain Annunciations demonstrate the impossibility of depicting God within the space of human geometry. This research in painting could be seen as closely linked to a conception of the divine that is not excluded, as Panofsky said, but present in the picture.

To support his argument, Arasse makes particular reference to a sermon delivered by St. Bernardine of Siena in 1427: the Annunciation is the moment when "immensity comes into measure [...], the unfigurable into figure, the uncircumscribable into place, the invisible into vision [... ], length into brevity, width into narrowness, height into lowness" ${ }^{5}$... all these conceptual paradoxes have given rise to spatial paradoxes from painters. Daniel Arasse also highlights how the most ingenious perspectivists enjoy toying with the rules of geometric perspective in order to show the paradox of the infinite entering into the finite.

\footnotetext{
4 Panofsky E., Perspective as Symbolic Form, New York, Zone Books, p. 65.

5 St Bernardine of Siena, De triplici Christi nativitate, in Opera Omnia, Venise, 1745, IV, p. 3, cited in San Bernardino de Siena, Pagine Scelte, Milan, 1950, p. 54.
} 


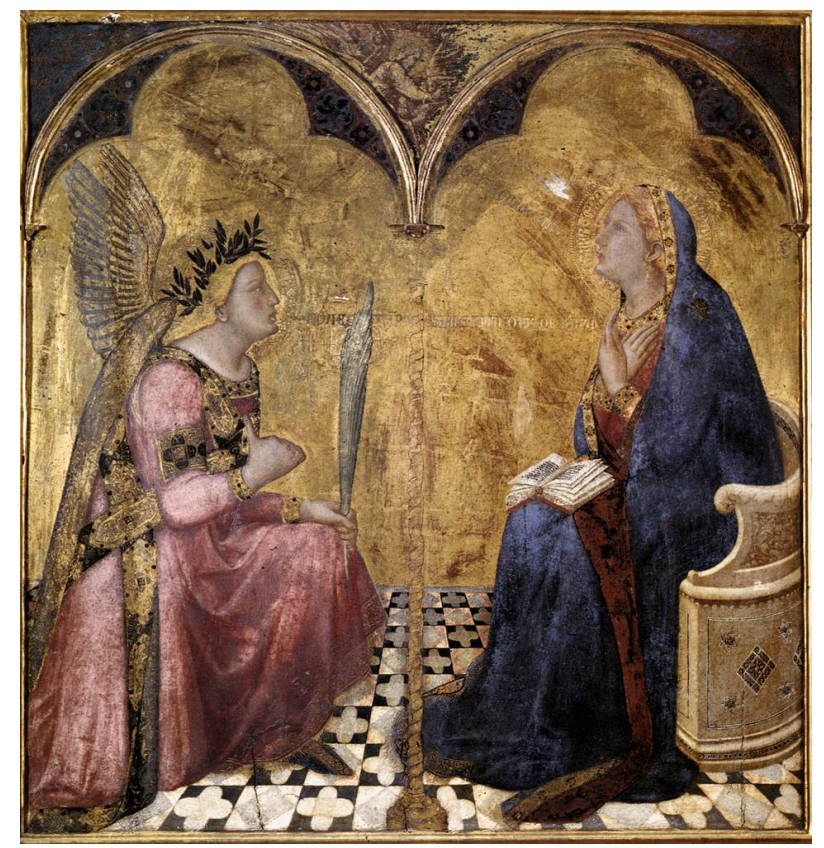

Ambrogio Lorenzetti, Annunciation, tempera on wood, Siena, Pinacoteca Nazionale, 1344.

In this Annunciation there is a column, often a symbol of Christ, very substantial at floor level and becoming fainter towards the top where it overlays and obscures the receding axis, one could say, at infinity, an explicit reference to God. Here, in 1344, we have an extraordinary innovation: a rigorously-drawn projective space. And then, through the effect of the geometry of this floor that goes from (wo)man to God, a new scene unfolds: God has His place here, hidden, far away at infinity, but present in the story that is being told. The Madonna, too, has a new human depth: her solid, three-dimensional body ushers in the expression of an emerging humanism. Perspective introduces God as the actual limit, at infinity, thus as the limit of a space that everything encompasses, including human spaces that replenish themselves. And the very first pictures painted in prospettiva were annunciations, that unique scene where infinite meets finite ${ }^{6}$. Then, with Piero della Francesca, this metaphysical dissertation in paint went on to also become a technique, without necessarily losing its religious essence. Piero's book De Prospectiva Pingendi (1475) is actually a treatise on "practical" projective geometry, the most significant mathematical text of his time, as Vasari was to write.

Hence prospettiva allows the painter to arrange the space of men and things and also to choose a viewpoint. The choice of where to place vanishing point determines the spectator's viewpoint; it proposes / imposes a line of sight - for instance, viewing, humbly from below, Antonello da Messina's Saint Sebastian the Martyr (1476).

\footnotetext{
${ }^{6}$ Longo S., "L’Annonciation en Italie. Enjeux méthodologiques et historiographiques, autour du colloque florentin de 1986", "'La perspective de l'Annonciation', présentation d'une étude de Daniel Arasse" and "L’intervalle sacré" in Studiolo, revue de l'Académie de France à Rome, X, 2013, pp. 24-32 and pp. 75-93.
} 


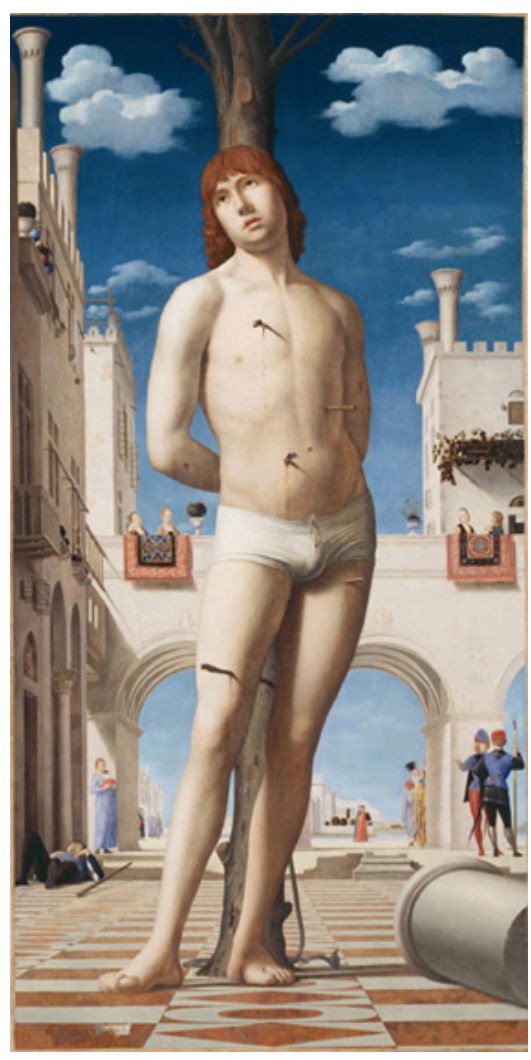

Antonello da Messina, St. Sebastian, tempera on wood transposed onto canvas, Dresden, Gemäldegalerie, 1476

And now this metaphysical and religious cosmology became a geometry of space: God, the stars and men found a new place in it, arranged from a unifying and changeable viewpoint. We have come a long way from the absolutes outside of space and the world of Byzantine mosaics, if we think back to Ravenna. This (re)arrangement of space, this new skill of choosing a viewpoint, this technology that soon spread across Europe, helped Copernicus (1473-1543) to "see" the solar system from "the Sun's viewpoint", the new prospettiva of modern science ${ }^{7}$.

In fact, the Renaissance invention of perspective involved the simultaneous invention of an explicit spatial structure and of a viewpoint, and even a "Copernican revolution" of this new and relativizing point, which we will come back to in the sciences. It was the consequence of a diametrical change: the viewer is no longer obliged to move in accordance with a system of contiguously-arranged scenes, he is the fixed point from which a continuous narrative starts out. This change is very significant, because it puts man in a different position in the space of action, or even in the Universe: Aristotelian physical space is the sum total of different scenes, it has no overall structure and gives form to a pictorial space conceived as the sum of the scenes of the historia. The ultimate expression of this idea were the spatial boxes of Giotto, as we have mentioned, and his fellow artists of the Trecento: "little houses", or rooms, are inhabited by protagonists in

7 This refers to a comment made in B.C. van Frassen's An introduction to the Philosophy of Space and Time, Random House, New York, 1970. 
various different, and often independent, narratives. The monofocal construction, theorized by Alberti in 1435, 90 years after Lorenzetti's early experiments, radically changed this method. Turning pictorial space into one unified body, albeit articulated into scenes (its limbs), gave this space the specific feature of being constructed from a single mathematical point, proposed by the painter, which also identifies the eye of the motionless viewer, in relation to whom everything is arranged.

The idea of a chosen, unique, immobile viewpoint was a theoretical leap, an epistemological mutation ${ }^{8}$. Painting thinks of the picture's hitherto closed space, as being open to the narrative "almost to infinity"9. As we have been taught by Hubert Damisch and Daniel Arasse, amongst others, painting thinks but, more than that, it shows. Linear perspective, which is Alberti's costruzione leggittima, is thus a geometrical abstraction that unifies the scenes of the narrative and, as such, it constitutes a theoretical break with earlier techniques. And so we have mathematical space.

\section{3 - Geometrical Optics and the Subject in Projective Space}

Painters and scientists of the $15^{\text {th }}$ century seem to have been familiar with geometrical optics, invented by Euclid and developed by the major Arabic-language schools of algebra and geometry. Some authors highlight the references Alberti makes to the "old school" who had made such a careful study of reflections on surfaces and the convergences of rays of light ${ }^{10}$. This was of course an analysis of lines in the finite, sometimes extended "eis apeiron", without limit, as in Euclid, thus potentially towards infinity, for instance in the calculation of angles subtending an object that is moving away from the eye. Ibn al-Haytham (Egypt, $11^{\text {th }}$ century) was one of the great masters of these calculations. But actual infinity, a difficult metaphysical judgment, was not to be found here, this projective point at the asymptotic limit which structures space and strength and imposes a viewpoint for every observer.

Geometrical optics, however, played a massive part in the work of painters from the $15^{\text {th }}$ century onwards; it introduced a new geometric rigour and augmented the figurative repertoire so as to better represent distance and arrange figures in projective space. But it was not at the origin of the metaphysical turning point, a century earlier, that had led to the pictorial invention of space that is being discussed here.

On the subject of this new technical rigour, in a rarely cited article Daniel Arasse takes the example of Brunelleschi's tavoletta, regarded as the first example of rigorous geometry in the prospettiva construction: he describes the actions of the Florentine engineer / architect when verifying his perspective representation of the Baptistry and suggests to the reader that the verification process, as related by Antonio Manetti in his biography of Brunelleschi, could be reversed.

Brunelleschi drew the Baptistry as seen from the entrance to Santa Maria del Fiore. He then made a hole on a level with vanishing point, and turned back to front the tablet with the drawing on. He put his eye opposite the hole and looked at the real-life Baptistry.

\footnotetext{
8 Michael Baxandall made a very subtle connection between Alberti's conception of painting and the oratorical art of rhetoric. See M. Baxandall, Giotto and the orators, 1340-1450, Clarendon Press, 1971.

9 Alberti L. B., On painting, I, 19.

${ }^{10}$ Simon G., "Optique et perspective : Ptolemy, Alhazen, Alberti", Revue d'histoire des sciences, 54, n³, 2001. pp. 325-350.
} 
Then he raised a mirror to the level of the drawing and looked at the reflection; by lowering the mirror and raising it again, he verified the conformity between what he saw before him and the lines of his drawing ${ }^{11}$.

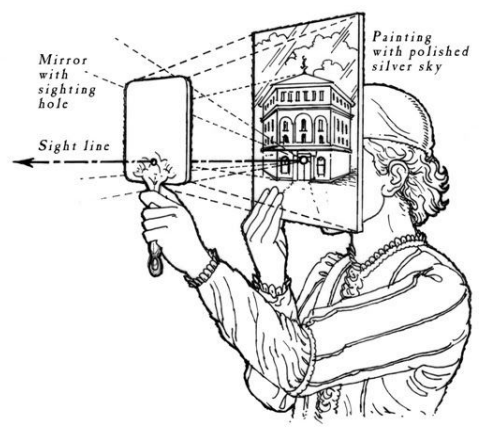

Daniel Arasse imagines the subject first looking at himself in the mirror, then raising his arm with the back-to-front tavoletta between himself and the mirror, and putting one eye to the hole pierced in the tablet to see the drawing. The reflection of the man looking at himself is hidden by the reflection of the Baptistry, and then, lowering the mirror, by the sight of the real-life building. "... The theoretical model of painting perspective consists in hiding the image of myself in the mirror, substituting it with the image of all that is visible"12.

This notion of reversing the steps in carrying out a verification process elevated by art history to the status of cognitive paradigm, leads us to compare the story of Brunelleschi's verification to the other founding myth of painting, the myth of Narcissus, whose face is annihilated in the spring. But in our case, the subject comes back. Because the viewpoint is always chosen by the painter, the choice of where to place the horizon is recommended by Alberti as the first thing to do. Thus, from the 1450s onwards, a horizon placed especially low or high reflects a precise awareness of the presence of a viewer, who will be struck by the effect of having a bird's eye view or a worm's eye view. In choosing the point of projection, the supposed position of the viewer determines the painting space. "What is of particular note there, is that the image does not exist without the person who created it"13. The modern notion of subject, painter, viewer, has been invented. ${ }^{14}$

These inventions can also be found under the brush of that other great "perspecteur", Andrea Mantegna, this time in a painting of a corpse. Not just any corpse, but that of the Redeemer, immediately after being taken down from the Cross, and not in his grave but on a marble surface. Through a sublime perspective foreshortening, we are placed right beside the feet of Christ and we look at Him not da sotto in su, but from feet to head. Mantegna's choice was bold, to the point where the Dead Christ is traditionally considered as the artistic legacy of the Paduan.

11 Manetti A., Opere Historiche, G. Milanesi, Florence, 1887, pp. 83-85.

12 Arasse D., "La peinture de la Renaissance italienne et les perspectives du Moi", in Image et signification, La Documentation française, Paris, 1983, p. 237.

13 Arasse D., "La peinture de la Renaissance italienne et les perspectives du Moi", op. cit., p. 238.

14 Sara Longo, Ph.D. thesis in Art History, Voir et savoirs dans la théorie de l'art de Daniel Arasse, under publication, Paris 1, Panthéon-Sorbonne, 2014. 
For a fuller understanding of the picture, let's start by looking at the studies. Among pictures recently attributed to Mantegna and published, we can see the research of a perspecteur, with a fondness for foreshortened corporeal representations, as in the preliminary drawings for the Dead Christ: the drawing is a study of Christ's body seen from the feet and then from the head, but always at a slight angle to the plane of representation, and not at 90 degrees, as in the final painting.

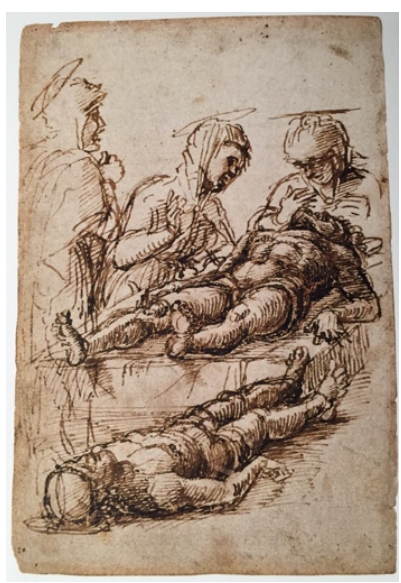

Andrea Mantegna, Study for the Dead Christ, pen and brown wash on paper, 1460-1465. Milan, private collection

During the same years, Paolo Uccello used the same technique. When his wife used to call for him at night, Vasari tells us, Paolo would join her in bed murmuring: "Oh! this perspective is such a lovely thing!" ... The elongated bodies in the Battle of San Romano give the battleground all its depth.

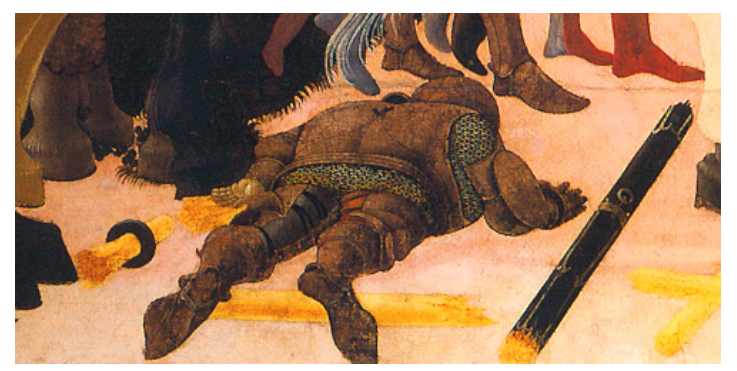

Paolo Uccello, Battle of San Romano, detail, 1456, tempera on wood. London, National Gallery

But the invention we noted in the Dead Christ is unique: the viewpoint chosen is that of the penitent, the faithful worshipper bending over the stigmata - perhaps the viewpoint of Mary Magdalene. Her vial of ointment is placed on the marble near to Christ's head. 


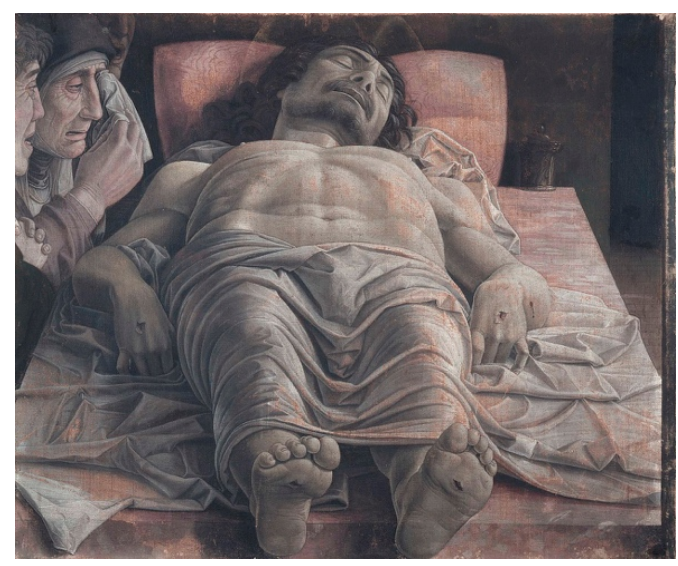

Andrea Mantegna, The Dead Christ, tempera on canvas, Milan, Pinacoteca di Brera, 1490

The head is resting on a cushion, also in light pink marble, so as not to detract from the mineral chromaticism of the whole of the painting (body, sheet and bed, everything is in stone). On the left, three figures mourn the corpse. At the bottom, is where we are. We look at this body and the painter has taken great care to show all of it: the soles of the feet and the backs of the hands torn by the nails, the lateral malleoli and the fibula and then, on the torso, the navel, the stigmata in the right side and the chest. Finally, on the face, the chin, mouth, nose, eyes, eyebrows, forehead and hair, everything is perfectly visible and identifiable.

A rigorous geometric perspective foreshortening derived from a simple calculation from a viewpoint, would never have permitted that. The forehead would have been hidden by the nose, the nose by the chin, the torso by the stomach, and above all, the feet would have been immensely bigger. The linearity of the perspective and the geometrical optics are deliberately overridden by the painter's decision. One can say, to put it positively, that the viewpoint is not exactly on a level with the feet, that we are slightly elevated and that the head of Christ is also raised, on the marble cushion. However, the impression of foreshortening is certainly there, we are at Christ's feet, but our worship extends to his whole body, hence it is the whole body that the artist must make visible. No realism in this, as is confirmed by the arms, which are connected to the upper body by strange and impossible muscles starting from beneath the chest. Anatomically, the body is monstrous; pictorially, it is perfect in its "monstration". In brief, perspective, which in appearance and in principle is so rigorous, is in no way absolute, and still less objective. It is a relative through which the observing subject fashions the form.

A final example, another Annunciation, painted by Piero della Francesca around 1470 for the Tertiary Sisters of the Order of St. Anthony of Perugia. 

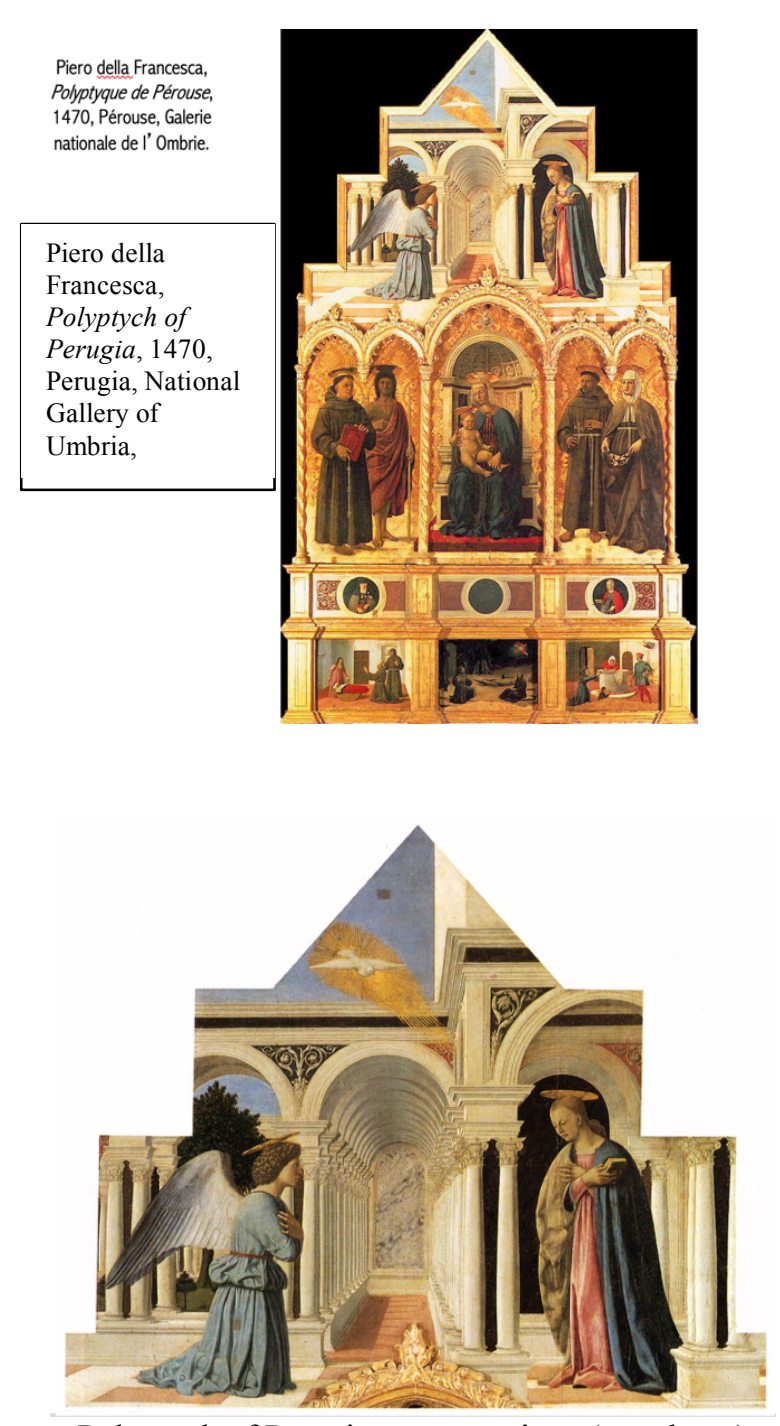

Polyptych of Perugia, upper register (see above)

The Annunciation that decorates the cyma of this large altarpiece is painted in a space that is not closed by the frame. Perspective thus makes it possible for Piero to give the illusion that what we see, which is cut into by the imposing stepped frame, is only one part of a much larger space, that of a cloister. Unlike in the middle register, where the golden background gives spatial unity but little depth, and in the lower register, a traditional predella where each scénette has its own closed, unified perspectival narrative space, the upper register shows an infinitely large space, to the sides (each architectural element exceeds the frame) and also in depth (the succession of columns is impressive). Gabriel is kneeling before Mary, looking up at her. Mary has her hands crossed and her head slightly bowed in a sign of acceptance. She is not in front of the architecture, as Gabriel is, but under a protrusion from the building. The reader should observe the clusters of columns to the right and left of the figure of Mary: they are the only elements of the painting placed in the foreground. The Virgin is directly opposite Gabriel, at the same distance from us, as we can see from their feet being on the same white strip of paving, behind the plinths. What is the visual effect of this arrangement of the figures in the architecture? 
Less than half a century ago, art historians with a special interest in perspective noted a paradox within the great geometric complexity of this painting. From Gabriel's viewpoint, Mary is invisible. She is hidden by the second cluster of columns that is not visible to us, as viewers, because we are at almost 90 degrees to the row ... but this cluster must be there, since opposite Mary, up above, two arches can be clearly distinguished. Thus she is bowing her head to the columns, not to Gabriel. Thomas Martone, who raised and discussed this contrivance, used the wonderful expression "trompe-l'intelligence" 15. Piero della Francesca, artist-surveyor par excellence, toys with the paradoxes arising out of a dual viewpoint, ours and that of the angel, not to trick our eye, but to trick our mind.

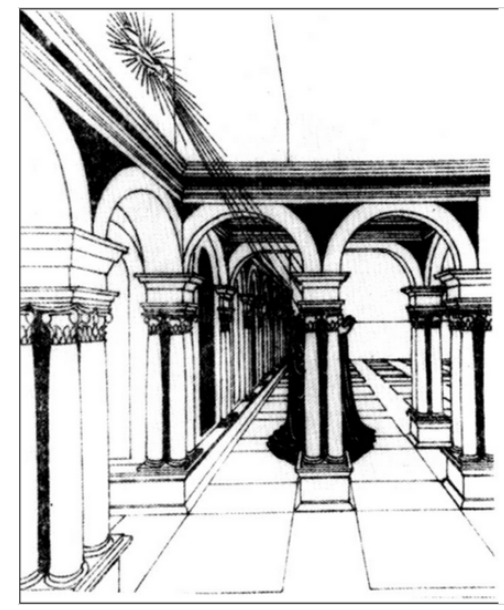

De Martone, art. cit.

We, the faithful in prayer, see Gabriel and Mary face to face and we contemplate their dialogue, their spiritual exchange which becomes the stuff of our prayers, our faith. We have to think that they see each other in order to speak to each other. But geometrically, rationally, Piero tells us (in secret), the pair cannot see each other, because they see each other in their minds, their dialogue is mute and blind. Theologically, there is between them the divine, the miracle in all its invisibility which is not explicable rationally, much less geometrically, but is made possible by the subtlety of the geometric arrangement of space. Because painting, in the Quattrocento, was not conceived of as simply the reproduction of "everything seen under the sun", whose "purpose is to please" (Poussin, 1665, letter to his friend Frédéric de Chambray). It is also the stuff of the invisible, of faith in a mystery that lines and colours are not there to explain but, through interplays of visibility, to show that there are mysteries ${ }^{16}$. The paradox emerges from applying geometry so rigorously as to make it possible to place the protagonists in a situation chosen theologically, and to do this in a way far removed from naïve realism. Driven by this paradox, the viewer has a dual role, visual and spiritual; geometric objectivity is

\footnotetext{
15 Martone T., "Piero della Francesca e la prospettiva dell'intelletto", in Piero teorico dell 'arte, Gangemi, 1985, pp. 173-185. See also Jean Petitot, Morphologie et Esthétique, Maisonneuve et Larose, Paris, 2004, pp. $75-84$.

16 On the issue of mysteries made visible and hidden, see the comments by Louis Marin, Opacité de la peinture: essais sur la représentation au Quattrocento, Usher, Paris, 1989.
} 
employed in the glances between the protagonists, in the viewpoints, in what is shown to the viewer and what is hidden. ${ }^{17}$

This interplay between relative and objective, anchored in the relationship with the space of the observing / knowing subject, in making a subjective viewpoint explicit in order for objectivity to be constructed, was to be at the heart of modern science through to the present day, as we will try to show. The pictorial form of the infinite in actuality, contributed to the invention of this space and of the scientific notion. Let us now explore various articulations, mathematical and practical, of this infinity and these spaces.

\section{4 - The Limit of Time, Calculus and Algebra}

First let us come back to the issue of infinity. Ever since Aristotle, time has been regarded as a paradigmatic potential infinity, because it is never present in its entirety in our mind. What "temporal" meaning could its projective limit have ${ }^{18}$ ? On the other hand, it is interesting to see this appearance in mathematics of an early symbolic expression of actual infinity, founded in religious debate, which came about via painting - explicitly mathematized painting, notably by Piero della Francesca, who as we have mentioned was an artist and a surveyor. This makes sense when we consider that the conceptual construction and geometry of an infinite space is not necessarily based on an actual infinite: Descartes' space can very well be conceived of as a potential infinite, an endless extension from its point of its origin. The actual infinite, however, is inherent in projective construction, especially when this is employed for the two-dimensional representation of a three-dimensional space. And vanishing point objectifies the actual infinite, by showing it, over there, at the back of the painting. In short, in the Renaissance, as a consequence of the central role of painting in the arts and the construction of knowledge (think of Leonardo da Vinci's drawings) - including theological knowledge three-dimensional space was conceived of mathematically, drawing it first; to make it intelligible (visible) on a plane, it was therefore necessary to project it, thus showing a (symbolic) form of this infinity of God, in actuality, that had been so clearly defined by the Christian philosophers of the Middle Ages.

Two centuries later, Desargues made this projective synthesis between infinity and geometry fully mathematical. In mathematical analysis, Newton and Leibniz proposed the concepts of derivative and integral as operations with infinite limit, at the heart of differential calculus. In the $19^{\text {th }}$ century, Cantor subsequently objectified actual infinity, through a syntax, associating it to a new, and this time scriptural, symbol, $\omega$. By algebraic manipulations, he generated from that an infinity of infinites, $\omega+1, \omega+2 \ldots$ and invented an arithmetic of infinites, $\omega+\omega, \ldots \omega \times \omega=\omega^{2}, \omega^{3}, \ldots \omega^{\omega} \ldots$, the transfinite ordinals.

17 We might here go back to Van Frassen's comment about Copernicus in the previous note: taking the Sun's perspective to observe the solar system and the game of hide and seek of the planets and their satellites is not "realistic"; more deeply, it is the invention of a scientific perspective.

18 In an attempt to make Relativity consistent with the Big Bang theory, some physicists conceive of the origin of time as an asymptotic inverse limit, i.e. the inverse of the temporal order created by the expansion of the universe. In fact, Noether's theorems (energy conservation as the invariant of the equations of motion through temporal translations) are at the heart of the relativistic turning point and are incompatible with an origin of time, see F. Bailly, G. Longo, Mathematics and Natural Sciences: the Physical Singularity of Life, Imperial College Press, London, 2011 (translation and revision of the book for Hermann, Paris, 2006). 
Nothing stabilizes a concept better than a mathematical praxis, the technical use of a sign for the concept, whose meaning will be enriched by this very usage. The debate on the infinity of God also interested Cantor, a deeply religious man: God is (at) the limit of all these limits, beyond transfinites. ${ }^{19}$

It should be noted that, in all these cases, mathematical infinity gives us a tool for the intelligibility of the world. In Renaissance painting, projective geometry, this theological decision, this asymptotic gesture, to infinity, arranges man's space for a fuller humanity, in its finitude. Likewise, from the spaces of Descartes and Desargues to the actual infinity of Newton and Leibniz, mathematical physics gave intelligibility to movement in the finite, around us, through the infinites of infinitesimal calculus. In logic, ever since Gentzen (1935), the ordinal analysis of proof has been based on Cantor's arithmetic of infinites $^{20}$. Moreover, Galileo had already explained to Simplicius, in the analysis of a mathematical sphere resting on a plane by a single point (a nonsense, said Simplicius), that mathematics is a science with infinite limit ${ }^{21}$. The finite makes a fetish of iteration and has become its prisoner ${ }^{22}$. The finitist-formalist who rejects infinity, declaring it to be outside the world and outside of physics, does not grasp the human meaning, for our designs and our praxes of intelligence, of this act of placing the infinite inside the world, while organizing this same world through language, geometry and writing, including asymptotic gestures.

An epistemology of this organizational concept can only be historical: a history of ideas and constitutive praxes, a critical history, to be kept constantly under review.

\section{5 - Rational Spaces: From Trade to Physics}

Thus the birth of modern science came about through the construction of an infinite space of possibilities, a space and a time of every possible phenomenon and all possible physical dynamics. The choice of origin of Cartesian coordinates provides the frame of reference within which all possible trajectories can be described and within which physics can be constructed, after Galileo. In fact, Descartes' analytical approach posits the origin and measurement of space, and gives it a prospettiva from which we are able to set the upper and lower bounds and understand the world. As an invariant of diverse mathematical representations, this space of all curves, of all trajectories, is doubtless made possible by a plurality of acts of experience. So, in the $16^{\text {th }}$ century also the mapping of new geographic explorations, joint to the Arabic optic ${ }^{23}$, contributed to a greater clarification of the geometric perspective, as a new framework for the world. In

${ }^{19}$ Charaud N., Georg Cantor, Infini et inconscient, Spartacus IDH, 2019: https://spartacus-idh.com/collections/nouvelles-visions-des-sciences.html\#

20 In fact, infinity comes into proof as an infinity between algebra and geometry, that of the "orderliness" of integers, G. Longo "Reflections on Concrete Incompleteness", Philosophia Mathematica 19 (3): 255280, 2011 (articles (co-)authored by G. Longo can be downloaded at https://www.di.ens.fr/users/longo/download.html )

21 A story that is a starting point for A. Gargani, It senza sapere Fondamenti, Einaudi, Turin, 1975.

22 Châtelet G., Les enjeux du mobile, Seuil, Paris, 1993.

${ }^{23}$ Kheirandish E., "The Manāzir Tradition through Persian Sources”, Les sciences dans le monde iranien, ed. Ž. Vesel, et al., Tehran, 1998 repr. 2004, pp. 125-45. E. Kheirandish, ed. and tr., The Arabic Version of Euclid's Optics: Kitāb Uqlïdis fì ikhtiläf al-manāzirir, 2 vols, New York, 1999. 
particular, Francesco Maurolico (1494 - 1575) developed a remarkable synthesis of the ideas of Islam's great mathematicians and algebraists, one aspect of the fertile marriage of Western and Eastern traditions in mathematics ${ }^{24}$.

In this context, the rich, innovative Galilean relationship between experiment and theory, physical theorizing itself, is intended to render phenomena intelligible and predictable: first we observe, we take measurements, and then the theory should generate a prediction that enables it to be verified. Scientific, or actually mathematical, forecasting of the future is thus placed at the centre of the intelligibility of the world proposed by modern science. And this prediction is made in the space and time of physical events, described mathematically by Cartesian analytical representation, enriched by what we can call "Galilean relativity": the modern space-time of physical phenomena was born out of an analysis of the transformation from a (Cartesian) frame of reference, one viewpoint, to another, while still preserving the laws of physics. More specifically, in the infinite space-time of possible trajectories, given a priori, invariants are described in terms of symmetries - the Galilean group of transformations between frames of reference in relative uniform-rectilinear (inertial) motion. This then is the objectivity of scientific law given by the relativity of frames of reference, the possible transformations from one into another: the relative makes the objective possible, as invariant under transformations of reference systems. It is however the subject who chooses these frames of reference, takes his place within them and settles on one viewpoint out of others, as did the painter, in positing the viewpoint for the viewer. The scientific certainty of the law (an invariant) thus allows prediction, calculation, and proves the theory.

We should however contextualize the shift towards the myth of rational prediction of a scientifically predictable future in the space of possibilities, as having likewise occurred in the early Italian Renaissance. The audacity of obtaining an insight into the future by rational means, within a given space of possibilities, can be traced back to the appreciation of progress and the ability to assess it quantitatively, in Italy in the $14^{\text {th }}$ and $15^{\text {th }}$ centuries. That was when the artisan technologies, large production facilities (the "arsenale di Venezia" which Galileo mentions) began to change the relationship with work and with the transformation of Nature herself ${ }^{25}$. And that was when we invented bank loans, in the same era as Lorenzetti's painting, also in Tuscany ${ }^{26}$. After that, mathematics played a massive part in this progress: Luca Pacioli $(1445$ - 1517), in particular, with his Summa de Arithmetica, Geometria and other writings, greatly developed the arithmetic of Fibonacci da Pisa (1170 - 1250) and invented the "partita doppia", a fundamental tool for finance and trade.

In short, in Italy, towards the middle of the $14^{\text {th }}$ century, money-lending became permissible, particularly in the form of "letters of credit" or paper money. Since it was no longer a sin, it was possible to bet on future progress, to obtain money from a bank, then to invest and to forecast the return of the money invested with calculable interest, and

\footnotetext{
24 Islami A., Longo G., "Marriages of Mathematics and Physics: a challenge for Biology" in The Necessary Western Conjunction to the Eastern Philosophy of Exploring the Nature of Mind and Life (K. Matsuno et al., eds), Special Issue, Progress in Biophysics and Molecular Biology Vol. 131, 2017, pp.179192.

25 Rossi P., I filosofi e le macchine, Feltrinelli, 1962 (ristampa, 2002).

26 The loan from the Bardi and Peruzzi Bank to Edward III, King of England, dated 1332. It was never repaid - as all Italian students and our colleague Alberto Peruzzi in Florence know perfectly well.
} 
thus to make personal gains, which was revolutionary both economically and conceptually. There was no longer any need for magic or divination in forecasting progress and in the ability to predict the future; rather it was a case of rational, or mathematical, knowledge. Of course, unknowns were possible, but within a pre-defined space of possibilities: in the same way as when you roll a dice, you take a chance, but out of six possible outcomes, no more and no fewer - and the symmetries of the dice give us the probabilities. Expectations and wagers are rational: one can assess the risk, in a preset space of finance, Pacioli, or a set of dice (G. Cardano, Liber de Ludo Alea, 1560; G. Galilee, Sopra le scoperte dei Dadi, 1612).

Hence was born the society of forecasting future progress from a predetermined list of possible dynamics. A society in which we can take the risk of borrowing and lending money and constructing scientific knowledge within a mathematically predetermined, albeit infinite, space of future trajectories; a science where it is possible to predict, by using a scientific theory, the result of an experiment or an economic or commercial activity. Painting, as we have seen, made these spaces of human action geometrically possible by a vertiginous cross-contamination with the infinity of God. And scientific objectivity has been achieved through making explicit the relativity of the viewpoint, highlighting the role of the subject who observes, this viewer who is not neutral in his relationship to space, to the point of being able of "forcing" how to see, beyond or even against the linearity of the costruzione leggittima, as with a great master of perspective, Mantegna.

\section{6 - Setting A Priori Conditions of Representation and Knowledge}

The revolution inspired by the pictorial use of perspective and its theorization was summarized in 1500 in Pomponio Gaurico's De Sculptura: before painting an object, the painter must construct the spatial frame (the locus) to contextualize it - the "locus" precedes the bodies that inhabit it. Panofsky makes explicit reference to Gaurico in order to highlight the birth of a Kantian vision of space as an a priori or a "condition of possibility" for practising science ${ }^{27}$.

After Newton, Kant posited space and time as a priori conditions of possibility of scientific construction: technically, in order to write and solve equations we must first give all the relevant parameters and functions' target domains.

Then in the $18^{\text {th }}$ century, Lagrange and Laplace gave us the mathematics of modern "state determined systems". Indeed, in solving Newton's equations in Descartes' and Galileo's spaces, "we should be able to predict all the facts of mechanics" (of celestial mechanics, Laplace said, but in fact he was referring to all the facts of physics). Pascal's and Laplace's mathematical analysis of probability also treats unpredictability as random, but a randomness that has nothing to do with determination, to be analyzed in terms of probability, thus in some measure on a space of all possibilities. In any case, for them,

\footnotetext{
27 An extensive synthesis of the debate on the birth of the modern-day concept of space and the role of perspective, from Gaurico to Panofsky, can be found in V.De Risi's "Arte e scienza della Sfera. La nascita del concetto moderno di spazio fra la teoria rinascimentale della prospettiva e la geometria di Leibniz" Sphaera Forma immagine e metafora, tra Medioevo ed Età Moderna, Olschki, Roma, 2012. Concurring with Damisch and Arasse, we have highlighted the interplay between theology and humanism that lies at its origin.
} 
unpredictable events take place within the infinite but predetermined Cartesian space of all possible trajectories and all possible facts. In the $19^{\text {th }}$ century this space was generalized to phase space, i.e. the space of relevant observables and parameters: to energy we associate time, to momentum we associate position. Here we have one possible path that takes us from the unified space, often a room or a courtyard, within which the meeting took place between the infinity of God and the finite of a woman, to the very general spaces of contemporary mathematical physics. The rigorous, infinitary, perspectival, structuring of this room or courtyard is a fundamental historic transition.

At the end of the $19^{\text {th }}$ century, in these mathematical spaces Poincare integrated the unpredictable into determination, by showing us the unpredictability of perfectly deterministic dynamics. In a quite different way, quantum mechanics introduced randomness into theory, in the form of intrinsic indeterminacy. However, the spaces of possible "trajectories" and events, of phases, will always remain mathematically predeterminable, whether they are infinite, from Descartes to Poincaré, or whether they are infinite dimensional spaces - Hilbert or Fock spaces in quantum mechanics. In these spaces, the trajectory of a law of probability, determined by the Schrödinger equation, beyond ordinary space-time, determines the quantum dynamics; measurement projects this dynamic of probability onto a real number, a probability value; jointly, they yield the nondeterministic character of quantum mechanics. It follows that this theory also gives $a$ priori the spaces of possible evolutions that can satisfy the most unpredictable quantum event, such as the creation / annihilation of a quanton. Thus, in the $20^{\text {th }}$ century, as in Renaissance perspectival inventions, the subject was to come back again, on a massive scale, into scientific construction: a quanton is the result of interaction between the subject, with his eyes on the measuring device, and microphysical "reality" - it takes shape and changes shape, it constitutes itself, under those eyes. And, in new forms, the knowing subject comes back.

We should note, and this is important, that the finite description of these infinite spaces, from Cartesian spaces to infinite dimensional quantum spaces, is made possible by their regularities: these are given in terms of mathematical symmetries, in other words as sets of invariants and transformations preserving these invariants. Symmetries make possible the finite synthesis, i.e. formal and axiomatic, of infinite and even infinite dimensional spaces; chance, even quantified, will be mathematically regulated, it will remain within the predefined space of possibilities.

Finally, we should note that in the fertile explorations of the Renaissance painters, we catch a glimpse of an inverted paradox of chance and space, perfectly unrealistic, in one of the paintings from which we have looked at a detail, one of Paolo Uccello's three Battles of San Romano. The "Cartesian axes" of the plane are provided by the broken spears and halberds, which, having fallen randomly in the chaos of battle, are strewn across the ground in a perfectly orthogonal way, thereby generating space. 


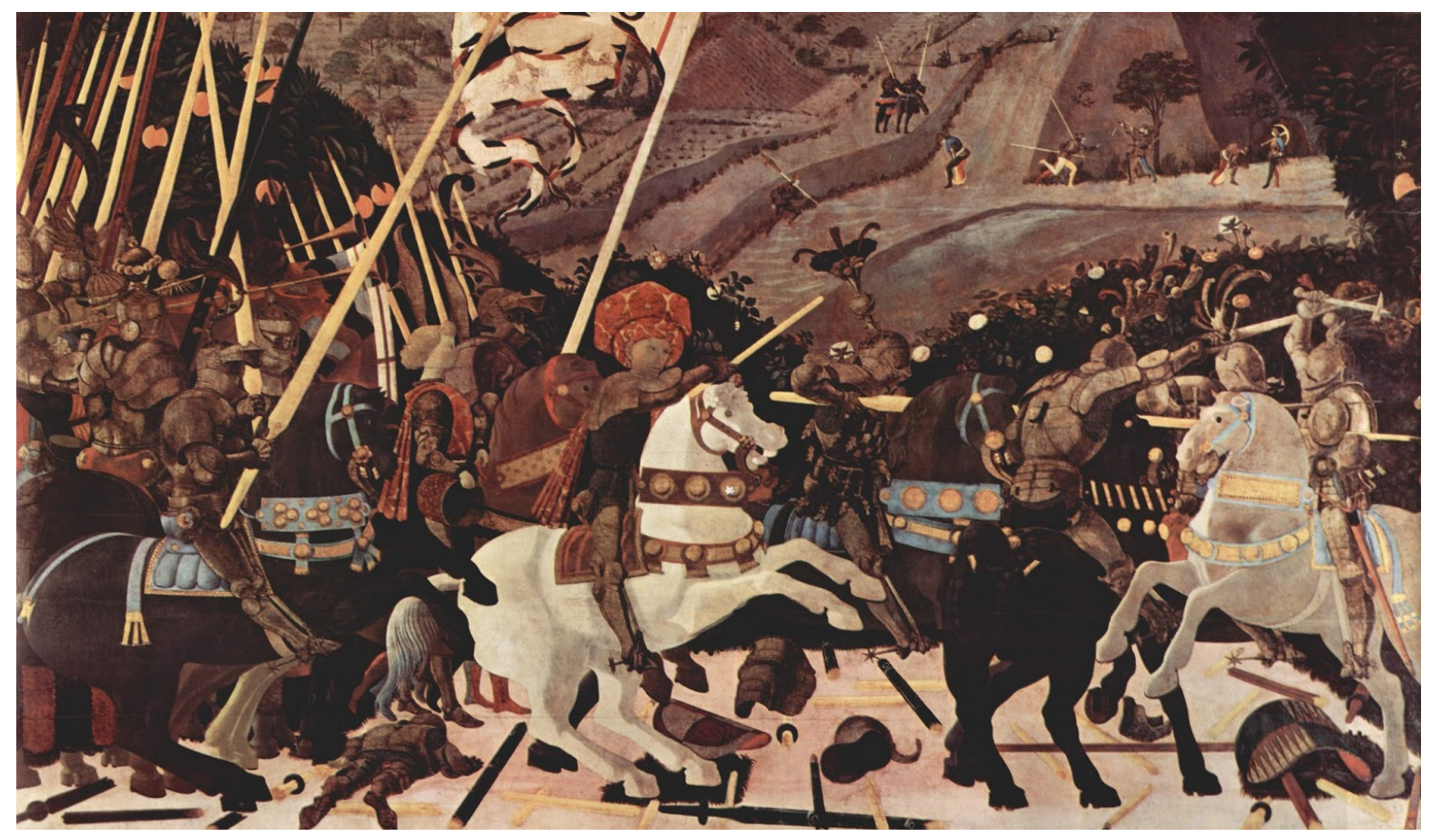

Paolo Uccello, Battle of San Romano, 1456, tempera on wood. London, National Gallery

In conclusion, in this section we have tried to reconstruct a constitutive path of the power of the mathematics of infinite spaces of all the possibilities of physics, even when these possibilities are given in terms of (quantum) probabilities, starting from a theological origin that found its first symbolic expression in $14^{\text {th }}$ century painting.

\section{7 - Spaces of Possibilities for the Evolution of Life?}

This is where we are having an issue today: in the analysis of life phenomena, not only biological but also societal phenomena, there is no way to predetermine (mathematically) that space of possible evolutions, the "phase space" of life. Let's try to further clarify this idea. The randomness of throwing a die or a coin, or of a quantum event, operates, as we said earlier, in a predefined (infinite) space of possible dynamics and results. We have learned how to obtain mathematical infinites, from Lorenzetti and Piero della Francesca, Descartes, Desargues, Newton, Cantor and Hilbert. Their symmetries (mathematical invariants) allow us to define these spaces (of phases, of possibilities) geometrically and formally.

However, there is no way to predetermine the space of possible future phenotypes (biological forms and functions) over the course of evolution - and phenotypes, i.e. organisms, are the biologically relevant observables. There was absolutely no sign of mammals' noses in the "forms" or the bacterial DNA of 800 million years ago. Neither could we have put on a list of possibilities the internal bones of their ear, as derived from the double jaws of a few vertebrates (gnathostomes) from 250 million years ago (an 
example of "exaptation", ex-post adaptation ${ }^{28}$ ): every phenotype is the result of historical events, of a vast genetic network and of evolving, changing epigenetic interactions.

But even the list of possible biological events over the coming centuries cannot be found in mathematically predeterminable spaces: in the course of evolution, phenotypes and ecosystems co-constitute themselves and jointly produce the space of possibilities, from the niches that each organism constructs in and with its environment. And the slightest fluctuation in these interactions, internally, i.e. between the different levels of organization, does not merely change "trajectories" in pre-given phase spaces, as in physical dynamics, but the spaces themselves. Symmetries, in other words the transformations that define invariance and which used to govern physics magnificently, are being continually changed because biology is the never-identical iteration of a morphogenetic process, beginning with cell reproduction right through to the most complex morphogenesis, which simultaneously co-determines the structure of the ecosystem. Structural stability preserves some global symmetries (e.g. the basic organizational plans or Bauplan), but each mitosis represents a symmetry change and breaks the physico-mathematical invariance: the two new cells are never identical, not even to the mother cell. This "never-identical" - a diversity in proteome, DNA, membranes, chromatin etc., the reconstitution of the matrix of a tissue, after mitosis in a multicellular organism - is a symmetry change.

And this is fundamental to the existence of the variability and diversity that make evolution and ontogenesis possible. The diversity of each embryogenesis, lower or higher (Goldschmidt's "hopeful monster" could be one result) pertains to the production of evolutionary changes. Because these constant changes (of symmetry), especially in the context of relevant observables, phenotypes, lie at the heart of variability, hence diversity and the very possibility of the living state of matter. They enable selectivity from amongst new forms, and adaptability, and they contribute to alterations in the ecosystem. In short, for us, the phylogenetic and ontogenetic trajectory of an organism is a cascade of symmetry changes ${ }^{29}$.

Clearly, exclusively molecular, or genocentric, analyses, where the observables are in fact pre-definable, are inherently incomplete, though still very useful: they cannot even describe the hereditary transmission of certain acquired deformities of the membrane of ciliates, or even their lipid structures ${ }^{30}$, or proteome dynamics in induced modifications inherited from the lactose operon - thus, in this case, even at the purely molecular level.

Mathematics is a science of invariants and of invariant preserving transformations, and thus a science of symmetries. Will we be able to invent new mathematics to deal with continual symmetry changes? Why not? The founding fathers invented their tools, the mathematics of invariance, from Euclid to Newton and Riemann and Grothendieck - his notion of "topos" as a categorical, very broad notion of space is currently the upper limit of a philosophy and practice of mathematics as a science of invariants and the

28 Gould S. J., The Structure of Evolutionary Theory, Harvard U. Press, 2002.

29 For a general framework in this perspective, see Soto A., Longo G., Noble D. (eds.), From the Century of the Genome to the Century of the Organism: New Theoretical Approaches, a special issue of Progress in Biophysics and Mol. Biology, Vol. 122, 1, Elsevier, Amsterdam, 2016.

30 Cavalier-Smith, T., "The membranome and membrane heredity in development and evolution", in Organelles, Genomes and Eukaryote Phylogeny: an evolutionary Synthesis in the Age of Genomics (R. P. Hirt \& D. S. Horner eds.), pp. 335-351, FL: CRC Press, Boca Raton, 2004. 
transformations that preserve them - we have come on long journey from Lorenzetti, but he played a part in opening the way. In any case, we must dare to invent, in order to address life as well as any historical science, such as economics, well away from the absurd theories of equilibrium in pre-given spaces: no ecosystem or economic system is in a state of equilibrium, nor approaching equilibrium, with its unique pre-given space of geodesics, unless all its "agents" are dead. Not only is life a process far removed from equilibrium, but it is permanently in "transition", at a critical threshold: from a mathematical viewpoint, it is (in) an "extended critical transition" (See Bailly, Longo, cited). Like the economy, it is always "in crisis", that is, from our perspective, it continually changes space of possibilities and its symmetries.

\section{8 - Conclusion and Opening: Heterogeneous Spaces of Biological Evolution}

We have tried to sketch a possible common thread, down through history, of the mathematical concept of space, so deeply interwoven with that of infinity. Explicitation of the role of the knowing subject is another part of it, in a complex interplay with the "relativizing" construction of scientific objectivity. The theological-pictorial origins of modern physico-mathematical space give it especially deep roots and make it an a priori that appears to escape scientific criticism. Its transition from theology to mathematics via painting, is the thesis being put forward here. And yet, epistemology enriched with a possible history can help change attitudes and practice, in terms of the constitution of our spaces of knowledge.

The challenge of the changing dynamics of the space of possibilities arises in any historical science, as we have said. In particular, nothing in biology can be understood other than in the light of a temporal perspective, of a specific historicity, that of evolution $^{31}$. This history is characterized by the emergence of new "phase spaces" or, to be more precise, new observables, Darwinian phenotypes and organisms. We have mentioned the emergence of the inner ear of vertebrates; out of many other examples we could cite another one, which has to do with the "dimensions of time" as a tool of intelligibility: biological rhythms, such as breathing, the heartbeat etc. came about in the course of evolution and they differ from physical frequencies. These rhythms are better understood if they are inscribed in a second time dimension, which implies a new observable and its own mathematical space ${ }^{32}$.

Three books and several articles written in collaboration with Francis Bailly, Maël Montévil and, jointly edited with Ana Soto (see http://www.di.ens.fr/users/longo/ ) outline new conceptual frameworks to better understand the physical singularity of the living state of matter: the change of perspective on symmetries is at the heart of a scientific proposal of this nature. The concept of a space of pre-given possibilities, hence invariant, a fundamental symmetry in physics, where, after Lorenzetti, we can even include God, will no longer suffice. Predictability, even the predictability of the space of

31 Dobzhansky, T., "Nothing in Biology Makes Sense Except in the Light of Evolution", American Biology Teacher, 35 (3): 125-129, 1973. For a modern-day view: Montévil, M., "Historicity at the heart of biology", Theory in Biosciences, to be published, 2020.

32 For a recent comparative survey, see Longo, G., "Confusing biological twins and atomic clocks. Today's ecological relevance of Bergson-Einstein debate on time", Conference "What is Time? Einstein and Bergson 100 Years later", April 4-6, 2019 (proceedings in preparation, Campo, Ronchi eds), 2020. 
possibilities, is no longer central to the construction of knowledge. This construction seeks to understand the historical contingency of life (and, potentially, of society - but we will not pursue our analyses that far). This should not interfere with our awareness of the role of our actions in a fundamentally unpredictable world, with no subtending space, in which we reach decisions as best we can, by making explicit the perspective (and values) that guide our actions.

In short, the theoretical challenge is therefore how to invent the tools designed to understand but not necessarily to predict, as René Thom has said. Darwin's theory of evolution does not predict anything, but it gives us an extraordinary framework for knowledge. Qualitative estimates of the impact of an activity can enable us to take action in the world, if these estimates are based on criteria for robust development such as diversity and adaptability.

Science is one of our active forms of being in the world, between knowledge and praxis. We also construct knowledge in order to take action in this world and we do actually need predictability, but it may possibly be provisional and qualitative, and one may be compelled to depart from the myth of these pre-given possibilities, as nice and soothing as Piero's spaces, while still keeping the focus on intelligibility, which leads to rational action. Attempts of a theoretical ${ }^{33}$ and mathematical nature are ongoing, such as those of the Cardano group ${ }^{34}$ and the "Post-structural Dynamics" team ${ }^{35}$ centred on a new differential calculus - whose operators generate their own spaces of possibilities ${ }^{36}$. In this, the inspiration of semiotics and dialogue with contemporary art is explicit.

33 Longo, G., "Naturalizing Physics. Or, embedding physics in the historicity and materiality of the living", Deleuziana, n. 11, special issue, "Differential Heterogenesis: Deleuze, Mathematics and The Creation of Forms", 2020.

34 http://cardano.visions-des-sciences.eu/fr

35 https:/enseignements-2019.ehess.fr/2019/ue/2691/

36 Sarti, A., Citti, G. \& Piotrowski, D., "Differential Heterogenesis and the Emergence of semiotic Function", Semiotica, issue 230, 2019. 